\section{MIERSITE, A CUBIC MODIFICATION OF NATIVE SILVER IODIDE.}

SILVER IODIDE is remarkable in being one of the few substances which undergo a contraction in volume as the temperature increases. This contraction is uniform until about $146^{\circ} \mathrm{C}$. is reached, when there is a further sudden contraction of considerable amount, after which the substance expands. The sudden contraction at $146^{\circ}$ is accompanied by a change in all the physical properties of the substance, the pale yellow, hexagonal modification which exists at ordinary temperatures, being then changed into a bright yellow, cubic modification. On cooling the reverse phenomena are observed.

From this behaviour it would be expected that only the pale yellow, hexagonal modification would be found as a natural mineral, and as a matter of fact the only pure silver iodide so far known is the hexagonal species iodyrite. The existence of a cubic modificatín has, however, long been suspected from the occurrence of iodine in the cubic mineral iodobromite (2AgCl.2AgBr.AgI). This probably represents the artificial cubic modification which is stable above $146^{\circ}$, in which case the natural crystals of iodobromite should be pseudo-cubic ; in fact, pseudomorphs of the hexagonal modification with the external form of the cubic modification. This would be strictly analogous to the pseudo-cubic leucite and boracite, which become isotropic when heated to a definite temperature.

The new mineral, miersite, is, however, quite distinct from these, and proves that silver iodide is trimorphous. The principal characters of the three modifications are :-

\begin{tabular}{|c|c|c|}
\hline Iodyrite & Miersite & Iodobromite \\
\hline Hexagonal & Cubic & Cubic \\
\hline Hemimorphic & Tetrahedral & Holohedral \\
\hline $\begin{array}{l}\text { Twin plane, a pyramid } \\
\text { face }\end{array}$ & A tetrahedron face & Not twinned \\
\hline Cleavage, perfect basal & $\begin{array}{l}\text { Perfect dodecahe- } \\
\text { dral }\end{array}$ & $\begin{array}{l}\text { Indistinct octahe- } \\
\text { dral }\end{array}$ \\
\hline Optically uniaxial & Isotropic & $\begin{array}{l}\text { Optically anoma- } \\
\text { lous? }\end{array}$ \\
\hline Sectile & Brittle & Sectile \\
\hline
\end{tabular}

Between these there is a remarkable crystallographic relation : when a regular octahedron is considered as a rhombohedral crystal, the angle $70^{\circ} 32^{\prime}$ corresponds to the angle $70^{\circ} 36^{\prime}$ between the basal plane and a pyramid of iodyrite; the tetrahedrism, twinning, and sometimes the peculiar development of the miersite crystals make this relation still more striking.

Iodyrite, in all its crystallographic characters, is practically identical with wurtzite $(\mathrm{ZnS})$, greenockite (CdS), and zincite $(\mathrm{ZnO})$; these are all hexagonal and hemimorphic, possess a basal cleavage, and are optically positive, while the axial ratios vary only very slightly $(a: c=\mathbf{I}: 0.8 \mathrm{IO} 9-\mathrm{I}: 0.8 \mathrm{I} 96)$. Many other substances may perhaps be included in this series, e.g. ice, magnesium, cadmium iodide, tridymite $\left(\mathrm{SiO}_{2}\right)$, \&c. In the same way the dimorphous cubic modifications miersite, blende $(\mathrm{ZnS})$, and marshite $(\mathrm{CuI})$ form another parallel series, since they are all exactly alike in crystallographic characters.

It will now be seen that the same relation exists between iodyrite and miersite as exists between wurtzite and blende. This forms, as far as crystallographic characters are concerned, a perfect example of an isodimorphous group, but apparently the only relation existing between zinc sulphide and silve iodide is that their simplest conceivable chemical molecules contain two atoms.

From these somewhat remarkable relations one is inclined to ask: why should there not be a third modification of zinc sulphide to correspond with iodobromite? or why should not all these substances (e.g. ice, \&c.) be dimorphous or trimorphous to fill up the gaps in these parallel series? Further, if nantokite and marshite are to be represented by the formula $\mathrm{Cu}_{2} \mathrm{Cl}_{2}$ and $\mathrm{Cu}_{2} \mathrm{I}_{2}$ respectively, then miersite should be $\mathrm{Ag}_{9} \mathrm{I}_{2}$ : these double molecules, however, only depend on the vapour density of cuprous chloride, but the gaseous molecule cannot be the same as the crystal molecule, especially when there are, as in silver iodide, possibly three types of the latter.

A detailed description of miersite will be published in the Mineralogical Magazine. It may now be mentioned that the two specimens preserved in the British Museum collection are from the Broken Hill silver mines in New South Wales; the associated minerals on one specimen are quartz, copper glance, and garnet, and on the other, malachite, wad and anglesite. The small crystals of miersite, which do not exceed $2 \mathrm{~mm}$. in diameter, are scattered over the surface of the matrix; they are of a pale or bright yellow colour, with an adamantine lustre. The only forms present are the cube and one or both of the tetrahedra, the latter usually differing in size but not in surface characters. In many respects the mineral is strikingly similar to the yellow blende which occurs in the white dolomite of the Binnenthal in Switzerland. The bright yellow streak is sometimes deeper in colour than the crystals themselves; this is strikingly shown by perfectly colourless and transparent crystals of marshite, which also give a bright yellow streak. Exposure to bright sunlight for several days does not affect the colour of the crystals. The silver is in part replaced by copper, and as this increases in amount, there is a gradual passage from miersite to marshite : "cuproiodargyrite" (AgI.CuI) from Chili is possibly an intermediate member of this group.

The new mineral has been named in honour of Mr. H. A. Miers, F.R.S., Professor of Mineralogy at Oxford, who first correctly determined the crystalline form of marshite, a mineral so closely resembling miersite in appearance that the two species are only to be distinguished by chemical tests.

\section{J. Spencer.}

\section{UNIVERSITY AND EDUCATIONAL INTELLIGENCE.}

THE Maryland Senate has passed a Bill granting 50,000 dollars a year for two years to the Johns Hopkins University.

Dr. Charles Chree, Superintendent of Kew Observatory, has received the honorary degree of LL.D. from the University of Aberdeen.

Mr. C. B. Rouss, who gave 25,000 dollars for a physical laboratory building in the University of Virginia, has given an additional 10,000 dollars for the same object.

Mr. Chester W. Kingsley, oí Cambridge, Mass, has given several large gifts to various benevolent purposes, including the sum of 25,000 dollars each to the Newton Theological Seminary, Andover Academy, and Colby University; the two first named being situated in Massachusetts, and the last in Maine.

A COURSE of eight Yates lectures in Archæology will be commenced at University College, London, on May 4, by Mr. J. Romilly Allen. The subjects of the first two lectures are the origins of primitive art and the evolution of decorative art, and the general object of the course is to trace the developments of Celtic art.

THE first school of forestry in America has just been created by the legislature of the State of New York, to be connected with Cornell University, and the sum of 10,000 dollars has been granted to cover the expenses of the first year. The school is authorised to purchase forest lands to the extent of 30,000 acres in the Adirondack region.

THE University of Paris has (says the Times) arranged for a loan of $1,700,000$ francs from the Crédit Foncier, repayable in 50 annual instalments, for the erection of new buildings in Paris and at Fontainebleau. The Faculty of Science is also about to order the construction at a cost of 25,000 francs of an equatorial, which, after figuring in the Exhibition of 1900 , will be placed in the tower of the new Sorbonne.

AT the graduation ceremony of the Glasgow University on April I2, the honorary degree of Doctor of Laws (LL.D.) was conferred upon Mr. Alexander Duncan, Secretary and Librarian to the Faculty of Physicians and Surgeons, Glasgow ; Mr. Douglas Dunlop, Secretary-General to the Department of Public Instruction, Cairo, Egypt ; Mr. John Inglis, formerly president of the Institution of Engineers and Shipbuilders in Scotland, president-elect of the Institution of Marine Engineers, London; Dr. Elie van Rijckevorsel, of the Batavian Society of Experimental Philosophy, Rotterdam; and Prof. J. M. Thomson, F.R.S., professor of Chemistry in King's College, London.

THE excursions of the London Geological Field Class will begin on Saturday, April 23, with a visit to Dorking, Box Hill, 
and Betchworth; and between that date and the middle of July the country from Aylesbury to Cuckfield will be systematically examined by the class so as to draw a section over the trough of the Thames basin, and see the deposits to the north and south of London, which underlie the rocks associated with the chalk. The class has been organised and carried on by Prof. H. G. Seeley, F.R.S., for the past twelve years, without difficulty of any kind, and without assistance. It was established as a class to show that systematic instruction in geology could be given in the open country, and the example it affords must tend to bring about more practical teaching in the matter of field-work. When the class began there was very little of such teaching anywhere, but the value of individual observation is now accepted as a canon of scientific education, and the success of Prof, Seeley's work should encourage educationists in their endeavour to get the fact-knowledge entirely substituted for the word-knowledge of books.

\section{SOCIETIES AND ACADEMIES DUBLIN.}

Royal Dublin Society, March r6.-Prol. G. F. Fitzgerald, F.R.S., in the chair.-Prof. J. Joly, F.R.S., and Dr. H. H. Dixon read a paper on the distribution of coccoliths and on some microscopic organisms found in Dublin and Killiney Bays. Coccoliths have been found by the authors on the Irish coast at Sligo, Slyne Head, Dingle, Waterville, and along the coast of south Co. Dublin, and on the south coast of England at Wey. mouth. Samples of water from Loch Inver and Portstuart did not afford any examples. Coccoliths were also found in the mud obtained in the Severn and Liffey beds. In the paper are also described a new marine Difflugia and organisms from Killiney Bay resembling Ehrenberg's Pyxidicula and Xanthidia from the chalk. - A paper by Prof. W. Noel Hartley, F.R.S., and Mr. Hugh Ramage was then read by the former, the subject being a determination of the wave-lengths of the principal lines in the spectrum of gallium, showing their identity with two lines in the solar spectrum. The authors have found gallium to be a very widely distributed element in the earth, and to be present also in meteoric bodies. It became natural to inquire if it is present in the sun. The wave-lengths of the two principal lines have not previously been determined by a grating spectrograph, and the authors availed themselves of the kind offer of Dr. Adeney to allow them to photograph spectra of gallium with the $21 \frac{1}{2}$ feet radius grating spectrograph in the Physical Labora. tory of the Royal University of Ireland. The two principal lines were photographed as bright and reversed lines in arc spectra, and as bright lines in the spark spectrum of a solution of gallium chloride. In these and in the oxyhydrogen spectrum of gallium compounds the less refrangible line is always stronge than the other. The wave-lengths of the two lines, determined by interpolation from adjacent iron lines, are found to be 4172.215 and $4033^{\circ} 125$. In Rowland's map of the solar spectrum there are two lines probably identical with these, namely:-

\section{I72.2II. Source : Aluminium. Intensity: I

$$
\text { and 4033112. Not identified. , }
$$

It is pointed out that gallium is present in every bauxite and shale examined by the authors, and also in metallic aluminium, and no doubt the line 4172.211 in the spectrum of aluminium is really a gallium line. From the very close agreement of the wave-lengths, from the relative intensities of the lines as shown above, and from the evidence of the wide distribution of the element, it seems certain that the two gallium lines are identical with the two lines above mentioned in the solar spectrum, and there are no other lines so close to these. The evidence is discussed at length in the paper, as also is the effect of the presence of elements upon the spectra of other elements.-Prof. J. P. O'Reilly read a paper on the occurrence of anatase and brookite in the quartzites of Shankill, Co. Dublin. He explained that the minerals were found in a mass of yellow earth, met with by the quarrymen in 1888 , and had only lately been examined. The peculiarity of the anatase was its approximation in composition to the clay or mineral analysed by Eakins as mentioned by Dana in his "System of Mineralogy," edition of 1892, p. 716 , while presenting the crystalline form of anatase, thus allowing of the presumption that the clay analysed by Eakins and called by him "Xanthitane," was probably the product of decomposition of an anatase having much the same composition as the mineral found at Shankill.

$$
\text { NO. } 1485 \text {, vOL. } 57]
$$

EDINBURGH.

Royal Society, March 21.-Lord Kelvin, President, in the chair.-Lord Kelvin, in a paper on thermodynamics, deduced from motivity, fulfilled a promise made twenty-one years ago to the Society. After referring to the somewhat misleading phrase, the mechanical equivalent of heat, and pointing out the necessity of having a single word to express the availability of heat for transformation into useful work, he proceeded to show that the whole of thermodynamics was contained in the two equations

$$
\begin{aligned}
& d e=\mathrm{JN} d t+\mathrm{\Sigma}(\mathrm{P} d g+\mathrm{JM} d g) \\
& d m=\mathrm{J} \frac{t-\mathrm{T}}{t} \mathrm{~N} d t+\mathrm{\Sigma}\left(\mathrm{P}+\mathrm{J} \frac{t-\mathrm{T}}{t} \mathrm{M} d g\right)
\end{aligned}
$$

where $e$ is the energy, $m$ the motivity, $t$ the temperature of any part of the system, $T$ the lowest temperature in the system, $g$ any coordinate, $\mathrm{P}$ the corresponding force, and $N$, M specific heats. The usual equations are at once deduced by treating $d e, d m$ as complete differentials.-Dr. Galt, of Glasgow University, communicated a paper on the microscopical appearances of the grains in the more commonly occurring starches. The paper was full of detail, and was illustrated by numerous original photographs and lantern slides. In a paper on methods of mapping rainfall, Mr. A. J. Herbertson described a simple graphical method for taking into account the varying lengths of perinds of observation of rainfall at different parts of the globe. The mean rainfall values were inserted on the maps in different coloured inks, according to the length of period of observation. The general trend of the isohyets could be attained by comparing similarly coloured means, and the final positions of the lines fixed by the values at the stations with the most extended records. The variableness in the length of the month is allowed for by drawing isohyetal lines, whose actual values are the nominal values multiplied by the days in the corresponding month, and divided by one-twelfth of a year ex pressed in days. In a second paper, on the normal rainfall of India and the abnormalities in 1896, Mr. Herbertson showed maps on the mean annual and monthly rainfall of India, based on the means published in the rainfall data for 1895, and those in the annual summary for 1896.

Royal Physical Society, March I6.-Mr. B. N. Peach, President, in the chair. - Papers were read by Mr. W. S. Bruce, of the Jackson.Harmsworth expedition, and Mr. William Eagle Clark, on the mammals and birds of Franz Josef Land. Mr. Bruce, who spent fifteen months on Franz Josef Land in 1896-97, explained that the number of species, exclusive of mammals and birds, he then obtained exceeded that of any previous Arctic ex pedition, he having secured 236 against 216 to the credit of the United States expedition of $1881-83$. He had at least doubled the number of species known to Franz Josef Land. He had found ancient reindeer horns, though there were no reindeer at present in the Land. Among the specimens he exhibited were the bones of whales and walruses found on raised beaches with an elevation of from $5^{\circ}$ to 80 feet, plainly indicating their great age; while one specimen - the scapula of a walrus - was found at a height of 336 feet. The chief point of interest in Mr. Clark's part of the subject, which was restricted to birds, was the finding of several new species-Bonaparte's sandpiper, purple sandpiper, and the shore lark. The first mentioned of these, Mr. Clark said, was not only a new and remarkable addition to the ornis of Franz Josef Land, but it was the first authentic example of this American species that had been obtained in Europe elsewhere than in the British Isles. Another subject of interest in the paper was the description of a newly-found nesting-place of the ivory gull. This was at Cape Mary Harmsworth, on what was considered to be one of the largest pieces of bare ground in Franz Josef Land. Of the twenty-two species of birds which formed the avifauna of Franz Josef Land, only ten had been found breeding, though several more undoubtedly nested there, while several, again, were mere stragglers.

PARIS.

Academy of Sciences, April 4.-M. Wolf in the chair.On a doctrinal point in the theory of quadratic forms, by $M$. de Jonquières. - Contribution to the study of Zeeman's phenomenon, by MM. Henri Becquerel and H. Deslandres. An account of some experiments on the influence of a magnetic field upon the periods of vibration of the radiations emitted by incandescent vapours. - Movements of the sensitive plant when grown in water, by M. Gaston Bonnier. The author has succeeded in cultivating Mimosa pudica completely immersed in 